\title{
High-capacity organic electrode material calix[4] quinone/CMK-3 nanocomposite for lithium batteries
}

\author{
Shibing Zheng ${ }^{1}$, Huimin Sun ${ }^{1,2}$, Bing Yan ${ }^{1}$, Jinyan $\mathrm{Hu}^{1}$ and Weiwei Huang ${ }^{1,3^{*}}$
}

\begin{abstract}
Organic lithium-ion batteries (OLIBs) represent a new generation of power storage approach for their environmental benignity and high theoretical specific capacities. However, it has the disadvantage with regard to the dissolution of active materials in organic electrolyte. In this study, we encapsulated high capacity material calix[4] quinone (C4Q) in the nanochannels of ordered mesoporous carbon (OMC) CMK-3 with various mass ratios ranging from 1:3 to 3:1, and then systematically investigated their morphology and electrochemical properties. The nanocomposites characterizations confirmed that $\mathrm{C} 4 \mathrm{Q}$ is almost entirely capsulated in the nanosized pores of the CMK-3 while the mass ratio is less than 2:1. As cathodes in lithium-ion batteries, the C4Q/CMK-3 (1:2) nanocomposite exhibits optimal initial discharge capacity of $427 \mathrm{~mA} \mathrm{~h} \mathrm{~g}^{-1}$ with $58.7 \%$ cycling retention after 100 cycles. Meanwhile, the rate performance is also optimized with a capacity of $170.4 \mathrm{~mA} \mathrm{~h} \mathrm{~g}^{-1}$ at $1 \mathrm{C}$. This method paves a new way to apply organic cathodes for lithium-ion batteries.
\end{abstract}

Keywords: organic lithium-ion batteries, nanocomposites, highcapacity cathode

\section{INTRODUCTION}

Lithium-ion batteries (LIBs) based on transition metal oxides serve as energy storage for electric vehicles and portable electronics, but they employ depletable metal, environmentally hazardous materials with high cost, deficient capacity and low energy density [1-4]. In contrast, the applicable organic electrodes should be low-cost, environmentally benign, green and sustainable [5-9]. Quinones are alternative candidates due to their good redox reversibility, multi-electron binding sites and abundant reserve in nature. Quinone compounds consisted of lightweight element-carbon, hydrogen and oxygen and usually showed much higher specific capacities [10-12].
For instance, benzoquinone with two electrons reaction delivers the theoretical capacity as high as $496 \mathrm{~mA} \mathrm{~h} \mathrm{~g}^{-1}$ [13]. Anhydrous dilithium rhodizonate $\left(\mathrm{Li}_{2} \mathrm{C}_{6} \mathrm{O}_{6}\right)$ with four active sites has high initial discharge capacity of $580 \mathrm{~mA} \mathrm{~h} \mathrm{~g}^{-1}$ [14]. However, for most organic electrode materials, low conductivity and high solubility in traditional organic electrolytes hinder their further implementation $[15,16]$.

Strategies to settle these problems are mainly focused on modification of the molecular structure, optimization of the electrolyte and preparation of nanocomposites. First, benzoquinone polymer (BQP) $\left(C_{\text {theo }}=404 \mathrm{~mA} \mathrm{~h} \mathrm{~g}^{-1}\right) /$ hydrobenzoquinone polymer (HBQP) with the incomplete cross-link structure displays relatively long cycling ability with capacity of $150 \mathrm{~mA} \mathrm{~h} \mathrm{~g}^{-1}$ [17]. Indigo carmine by introducing sulfonate group into indigo shows well cycle-life performance, but the corresponding theoretical capacity decreases from $204 \mathrm{~mA} \mathrm{~h} \mathrm{~g}^{-1}$ (indigo) to $115 \mathrm{~mA} \mathrm{~h} \mathrm{~g}^{-1}$ (indigo carmine) [18]. Obviously, polymerization or salt formation lead to the sacrifice of capacity and the introduction of "dead mass". The second method is using solid electrolyte and gel electrolyte to alleviate the dissolution of active materials. An all-solidstate lithium battery based on composite polymer electrolyte (CPE) and pillar[5]quinone cathode was fabricated, and showing with a cycling retention of $94.7 \%$ after 50 cycles, but its conductivity $\left(0.26 \mathrm{mS} \mathrm{cm}^{-1}\right)$ is still low [19]. Constructing nanocomposites is the third method to optimize electrode materials. The carbon materials act as a matrix to load the active material for LIBs [20]. Carbon fiber cloth/sulfur composites can also load sulfur for latemodel sodium-sulfur batteries cathode [21]. Mesoporous carbon (MC)/9,10-anthraquinone (AQ) composites show an initial discharge capacity of $222 \mathrm{~mA} \mathrm{~h} \mathrm{~g}^{-1}$ with a cycling retention of $43.7 \%$ after 50 cycles [22]. Usually, pore

${ }^{1}$ College of Environmental and Chemical Engineering, Yanshan university, Qinhuangdao 066004, China

${ }^{2}$ Department of Mechanical and Electrical Engineering, Qinhuangdao Institute of Technology, Qinhuangdao 066100, China

${ }^{3}$ Key Laboratory of Advanced Energy Materials Chemistry (Ministry of Education), Nankai University, Tianjin 300071, China

*Corresponding author (email: huangweiwei@ysu.edu.cn) 


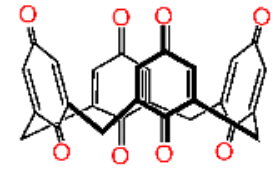

$\mathrm{C}_{28} \mathrm{H}_{16} \mathrm{O}_{8}(\mathrm{C} 4 \mathrm{Q})$

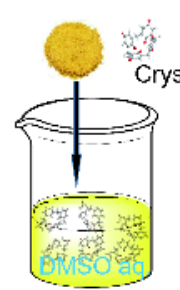

Crystal $\mathrm{C} 4 \mathrm{Q}$

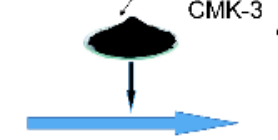

Ultrasound for $30 \mathrm{~min}$ at room temperature

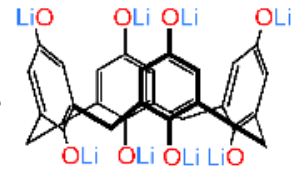

$\mathrm{Li}_{\mathrm{B}} \mathrm{C}_{2 \mathrm{~g}} \mathrm{H}_{18} \mathrm{O}_{\mathrm{g}}\left(\mathrm{Li} \mathrm{C}_{3} \mathrm{QQ}\right)$
Scheme 1 Diagram for (a) the proposed redox insertion/extraction mechanism of $\mathrm{C} 4 \mathrm{Q}$, and (b) the preparation of the composites.

diameter and pore distribution directly affect the cycling stability of the composites. CMK-3 shows smaller hole and more homogeneous pore diameter than $\mathrm{MC}$, leading to superior performance. For instance, Li et al. [23] prepared 2,2'-bis(3-hydroxy-1,4-naphthoquinone)/CMK3 composite with a discharge capacity of $308.3 \mathrm{~mA} \mathrm{~h} \mathrm{~g}^{-1}$, and it decayed to $132.9 \mathrm{~mA} \mathrm{~h} \mathrm{~g}^{-1}$ after 50 cycles at $0.1 \mathrm{C}$. These results demonstrate that the strategy of retarding the solubility and improving rate ability by encapsulation is feasible.

Previously, we reported calix[4]quinone (C4Q) with eight electrons reaction delivered a discharge capacities of $422 \mathrm{~mA} \mathrm{~h} \mathrm{~g}^{-1}$ for LIBs (Scheme 1a) and $438 \mathrm{~mA} \mathrm{~h} \mathrm{~g}^{-1}$ for sodium-ion battery (SIB), respectively [24,25]. Although gel polymer electrolyte for quasi-solid-state LIB exhibited good cyclic stability, the conductivity of gel electrolyte $\left(1 \times 10^{-4}-0.57 \times 10^{-3} \mathrm{~S} \mathrm{~cm}^{-1}\right)$ is 20 times lower than that of liquid electrolyte, leading to inferior rate performance. For SIBs, the C4Q/CMK-3 nanocomposites have shown fine electrochemistry cycling stability. Inspired by that, we systematically studied the nanocomposites prepared by encapsulating different ratios of $\mathrm{C} 4 \mathrm{Q}$ into $\mathrm{CMK}-3$. The nanocomposites as novel electrode materials for rechargeable LIB reveal an excellent initial capacity of $427 \mathrm{~mA} \mathrm{~h} \mathrm{~g}^{-1}$, fine cycle stability $\left(251.2 \mathrm{~mA} \mathrm{~h} \mathrm{~g}^{-1}\right.$ after 100 cycles) and high conductivity.

\section{EXPERIMENTAL SECTION}

\section{Material preparation}

The C4Q active material was synthesized through simple three-step coupling, reduction and oxidation reaction [26]. Scheme $1 \mathrm{~b}$ exhibits the simple impregnation method to acquire the nanocomposites. Different mass of C4Q was dissolved in dry DMSO, and then a certain amount of CMK-3 was added. The mixture was ultra-sonicated for $30 \mathrm{~min}$, then dried at $100^{\circ} \mathrm{C}$ under vacuum, and eventually the nanocomposites C4Q/CMK-3 (1:3, 1:2, 1:1, 2:1 and 3:1) were obtained.

\section{Characterization and electrochemical measurement}

The structure of the synthesized C4Q was identified by Fourier transform infrared spectroscopy (FTIR, FTIR-650 spectrometer), ${ }^{1} \mathrm{H}$ NMR and ${ }^{13} \mathrm{C}$ NMR (Varian UNITYplus $300 \mathrm{MHz}$ spectrometer). Electrospray ionization mass spectrometry (ESI-MS, CQ Finnigan) was used to measure the mass spectrometry and Vario EL to get the elemental analysis result. Thermogravimetry (TG) measurements were performed on a NETZSCH TG 209 under air atmosphere at a heating rate of $5^{\circ} \mathrm{C} \mathrm{min}^{-1}$. The samples were conducted by X-ray diffraction (XRD) with wide $2 \theta$ from $10^{\circ}$ to $80^{\circ}$ at $5^{\circ} \mathrm{min}^{-1}$ (D-max-2500/PC, Cu $\mathrm{Ka}$ radiation). The morphologies of the samples were observed on scanning electron microscopy (SEM, JEOL JSM7500F) and transmission electron microscopy (TEM) images (Philips Tecnai-F20). The pore volume and surface area were taken by $\mathrm{N}_{2}$ adsorption-desorption isotherms on a Belsorp-Mini Instrument.

The C4Q electrode slurry was prepared by grinding the mixture of an appropriate amount of $\mathrm{N}$-methyl-2-pyrrolidone (NMP), C4Q (60 wt.\%), conductive carbonsuper P (25 wt.\%) and polyvinylidendifluoride (PVDF) (15 wt.\%). The composite electrodes slurries were prepared by blending the composites ( $80 \mathrm{wt} . \%)$, conductive black-super P (5 wt.\%), and PVDF (15 wt.\%)/NMP. The slurry was coated on the aluminum foil and vacuumdried at $80^{\circ} \mathrm{C}$ for $10 \mathrm{~h}$. Then the electrodes were cut into circular pieces with an area mass loading of $\sim 1.4 \mathrm{mg} \mathrm{cm}^{-2}$. CR2032 coin-type LIBs were fabricated in an argon-filled glove box with $1 \mathrm{~mol} \mathrm{~L}^{-1} \mathrm{LiFP}_{6}$ in ethylene carbonate (EC)/dimethylcarbonate (DMC) $(1: 1, v / v)$ as electrolyte, Celgard 2400 as the separator and lithium as the counter electrode.

Cyclic voltammogram (CV) and electrochemical impedance spectroscopy (EIS) were conducted on CHI Instruments electrochemical workstation (CHI-660E). Land CT2001A was used to test the galvanostatic dischargecharge and rate performance within potential $1.5-3.5 \mathrm{~V}$ at diverse current densities. Both the assembly and testing process were performed at room temperature.

\section{RESULTS AND DISCUSSION}

FTIR (Fig. S1), ${ }^{1} \mathrm{H}$ and ${ }^{13} \mathrm{C}$ NMR (Fig. S2), ESI-MS (Fig. S3) and TG/DTA (Fig. S4) spectra indicate the successful 

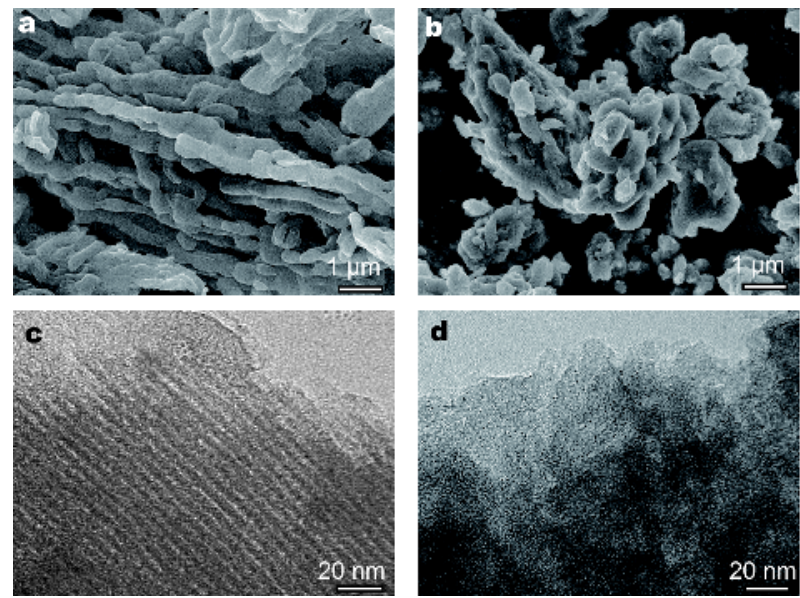

Figure 1 SEM images $(a, b)$ and TEM images $(c, d)$ of CMK-3 $(a, c)$ and C4Q (33.3 wt.\%)/CMK-3 (b, d).

synthesis of C4Q [26]. As shown in Fig. S5a and Fig. 1a, c, $\mathrm{C} 4 \mathrm{Q}$ is acicular crystal and CMK-3 is highly ordered porous fiber like texture with extremely high surface area. No C4Q particles are observed on the exterior of CMK-3 with the contents of $\mathrm{C} 4 \mathrm{Q}$ at $25,33.3$ and $50 \mathrm{wt} . \%$, suggesting $\mathrm{C} 4 \mathrm{Q}$ is fully loaded into the nanopores (Fig. S6). The surface of CMK-3 turns smooth and darkens progressively in Fig. 1b, d. Eventually, as the content of C4Q increases to $66.7 \mathrm{wt} . \%$, the nanochannels of CMK-3 are nearly filled up with $\mathrm{C} 4 \mathrm{Q}$ causing flakes powders (no crystals) to separate out (Fig. S6e, f).

$\mathrm{N}_{2}$ adsorption-desorption isotherms and pore size distribution (PSD) in Fig. S7a, b indicate CMK-3 has a specific surface area of $1,074.3 \mathrm{~m}^{2} \mathrm{~g}^{-1}$ and the corresponding pore volume of $1.276 \mathrm{~cm}^{3} \mathrm{~g}^{-1}$, which decreases to $258.0 \mathrm{~m}^{2} \mathrm{~g}^{-1}$ and $0.22 \mathrm{~cm}^{3} \mathrm{~g}^{-1}$ for the composite (1:2), respectively. Ultimately, both of the values are near to zero as the content of $\mathrm{C} 4 \mathrm{Q}$ further increases to more than 2:1. These results are consistent with the SEM images.

As depicted in Fig. 2, most of XRD diagrams of C4Q, CMK-3 and the composites are similar with the previous work $[22,23,25]$. However, in the amplified inset, the composites $(2: 1,3: 1)$ and the treated C4Q show a weak peak at $11.5^{\circ}$, caused by the superfluous $\mathrm{C} 4 \mathrm{Q}$ that exists in amorphous and crystalline morphology (Fig. S5b). The above results reveal the maximum encapsulation ratio of C4Q to CMK-3 is $1: 1$.

In Fig. S8, the CV curves of pure C4Q and the composites electrodes at the potential range from 1.5 to $3.5 \mathrm{~V}$ with a scan rate $0.2 \mathrm{mV} \mathrm{s}^{-1}$ show two well-defined redox peaks at 2.64 and $3.16 \mathrm{~V}$, respectively. For the $\mathrm{C} 4 \mathrm{Q}$ electrode, an obvious gap between the first and second circle area suggests the capacity fading, which is gener-

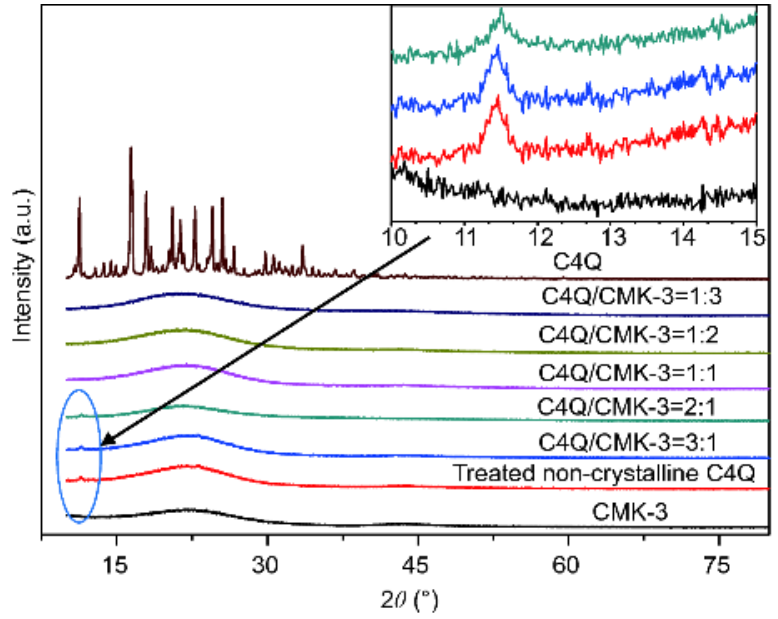

Figure $2 \mathrm{XRD}$ patterns of $\mathrm{C} 4 \mathrm{Q}$, treated $\mathrm{C} 4 \mathrm{Q}, \mathrm{CMK}-3$ and the composites. Inset image: corresponding partial enlarged drawing of the composites.

ated by the dissolution of active materials [25]. For the composites, CMK-3 restrains C4Q's dissolution, and thus the curves of the first and the second are overlapped.

The electrochemical results of C4Q and the composites are compared in Fig. 3. C4Q delivers an initial discharge capacity of $427 \mathrm{~mA} \mathrm{~h} \mathrm{~g}^{-1}\left(C_{\text {theo }}=446 \mathrm{~mA} \mathrm{~h} \mathrm{~g}^{-1}\right)$ following a reversible charge capacity of $412 \mathrm{~mA} \mathrm{~h} \mathrm{~g}^{-1}$ with broad discharge/charge plateau at $0.1 \mathrm{C}$, indicating eight quinone units participate in the Li-ion insertion/extraction process (Scheme 1a). Inevitably, its capacity rapidly fades to $27.9 \mathrm{~mA} \mathrm{~h} \mathrm{~g}^{-1}$ after 50 cycles (Fig. 3a). However, the composite (1:2) delivers a better stability upon cycling performance than that of pure $\mathrm{C} 4 \mathrm{Q}$ with a capacity of $251 \mathrm{~mA} \mathrm{~h} \mathrm{~g}^{-1}$ after 100 cycles at $0.1 \mathrm{C}$ (Fig. 3b). The specific nano-sized effect of CMK-3 makes the plateaus vanish $[27,28]$. The cycling abilities of $\mathrm{C} 4 \mathrm{Q}$ and the composites are compared in Fig. $4 \mathrm{a}$ within the potential of $1.5-3.5 \mathrm{~V}$ at $0.1 \mathrm{C}$. Both C4Q and composites deliver similar capacities, but their cycle abilities are quite different. The composite (1:3), theoretically, has a better cycle ability than other composites, but this prospection only be maintained in the first 20 cycles. The gradual effusion process of active material mainly accounts for this consequence. The composites (1:3, 1:1 and 2:1) and C4Q show discharge capacities of 185, 124, 103 and $13.1 \mathrm{~mA} \mathrm{~h} \mathrm{~g}^{-1}$, respectively, whereas the composite (1:2) has optimal cycling ability. In brief, the encapsulation method can greatly enhance the cycling ability of organic materials.

As shown in Fig. 4 b, the rate capability of $\mathrm{C} 4 \mathrm{Q}$ decays rapidly to $13.2 \mathrm{~mA} \mathrm{~h} \mathrm{~g}^{-1}$ at $1 \mathrm{C}$, while the composite (1:2) delivers a discharge capacity of $251 \mathrm{~mA} \mathrm{~h} \mathrm{~g}^{-1}$ (approxi- 

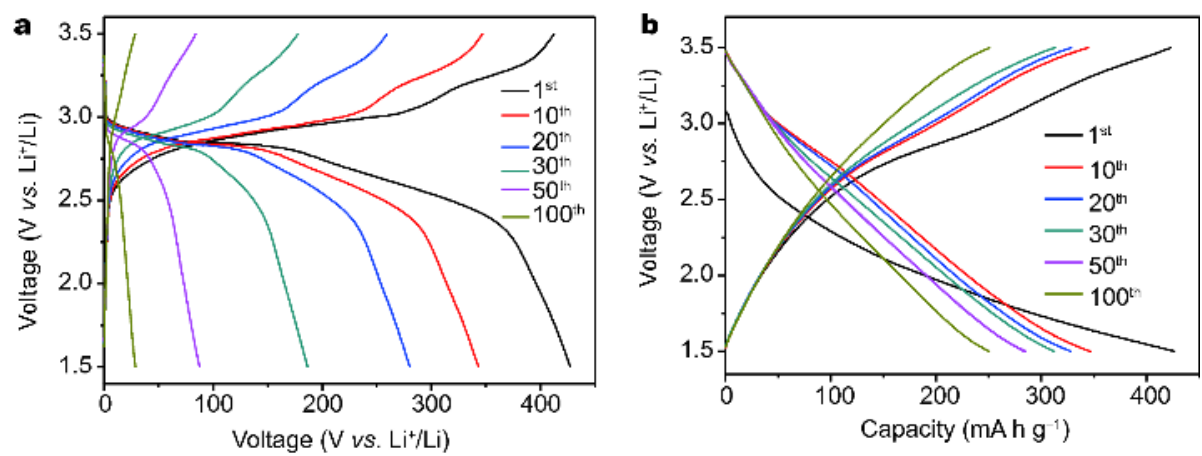

Figure 3 Discharge-charge curves of (a) C4Q and (b) C4Q/CMK-3 (1:2) at $0.1 \mathrm{C}$.
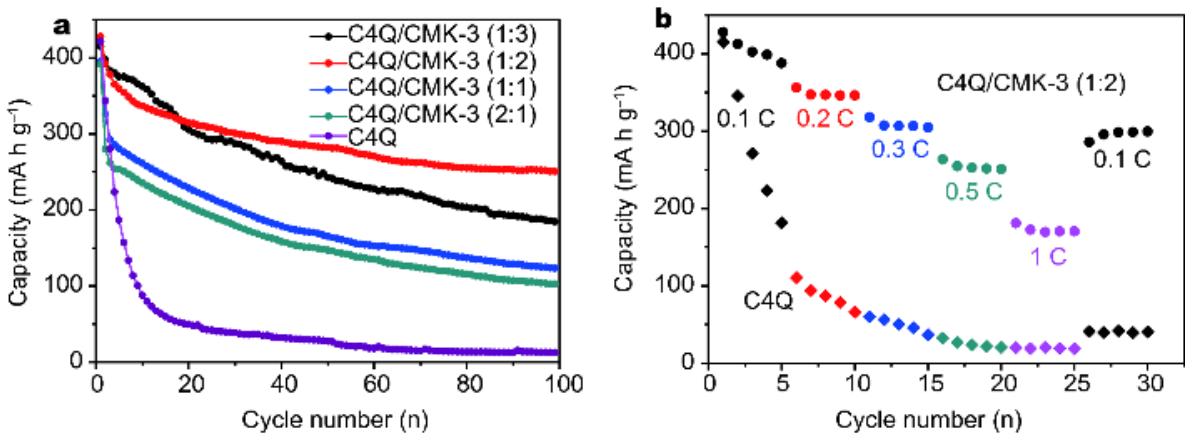

Figure 4 (a) Cyclic performance of C4Q and C4Q/CMK-3 composites at $0.1 \mathrm{C}$, (b) rate discharge capacities of C4Q and C4Q/CMK-3 (1:2) composite between $0.1 \mathrm{C}-1 \mathrm{C}$.
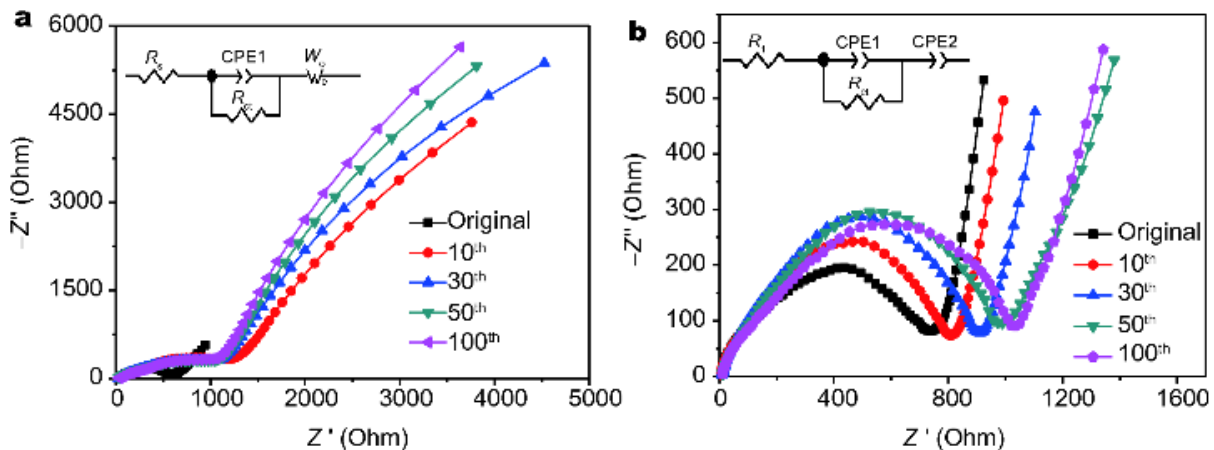

Figure 5 Impedance spectra of (a) C4Q and (b) C4Q/CMK-3 (1:2) for LIBs in different cycles at room temperature. Insets are the corresponding equivalent circuit, $R_{\mathrm{ct}}$ is the charge-transfer resistance, $W_{0}$ is the Warburg impendence and CPE is the double-layer capacitance.

mately 19 times higher than that of $\mathrm{C} 4 \mathrm{Q}$ ) at the same cycle. Namely, the porous CMK-3 with facile electron and ion transport promotes the rate performance of the composites.

Conductivity of C4Q and composite (1:2) was gathered in Fig. 5 by EIS analysis at $3.0 \mathrm{~V}$ ranging from $10^{-2}$ to $10^{5} \mathrm{~Hz}$, and the insets in Fig. 5 are the equivalent circuits of the Nyquist plots. $R_{\mathrm{s}}\left(\mathrm{C} 4 \mathrm{Q}, 22.93 \Omega\right.$ ) and $R_{1}$ (composite $1: 2,1.35 \Omega$ ) are the Ohmic internal resistance, indicating
CMK-3 can decrease the electrical resistance of the anode and cathode materials. Moreover, the composite has lower charge transfer resistance $\left(R_{\mathrm{ct}}\right)$ than pure $\mathrm{C} 4 \mathrm{Q}$ cathode at the same cycle $\left(R_{\mathrm{ct} 10}(\mathrm{C} 4 \mathrm{Q})=1,446 \Omega, R_{\mathrm{ct} 10}\right.$ (composite $1: 2)=873.3 \Omega$ ). Interestingly, the chargetransfer resistance increases rapidly during the first 10 cycles and decreases in the succeeding cycles associated with dissolution of $\mathrm{C} 4 \mathrm{Q}$ at the first few cycles, and then only carbon remains on the electrode. Constant phase 


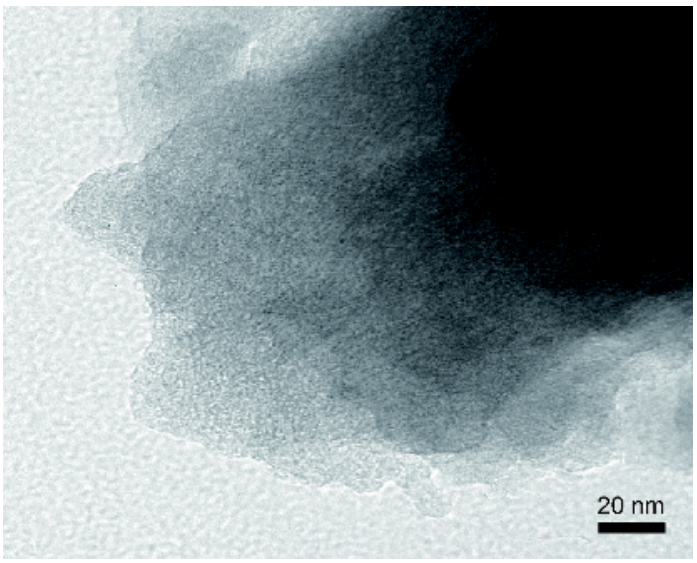

Figure 6 TEM image of C4Q/CMK-3 after 100 charge-discharge cycling.

element (CPE) represents a double-layer capacitance caused by porous surface. $W_{0}$ is the Warburg diffusional impedance of $\mathrm{Li}^{+}$into the composites electrode, and the impedance of the composites increases steadily because CMK-3 alleviates the dissolution of C4Q. Even so, the resistance of composite $(1: 2)$ is still lower than the pure C4Q electrode, suggesting the method of encapsulation is feasible to enhance the conductivity of organic materials.

Ultimately, the TEM image of the composite (1:2) electrode after 100 cycles for further dissecting the function of CMK-3 shows fasciculate morphology with smooth surface and no obvious porous structure (Fig. 6). The morphology of CMK-3 is stable and C4Q is still confined in the nanochannels during the whole test process. Hence, the cycling life of the organic materials extends.

\section{CONCLUSIONS}

To summarize, we demonstrate an easy strategy to prepare mesoporous carbon supported organic composites electrode materials that integrates the advantages of C4Q-high energy density, green sustainability with superior conductivity of CMK-3. The composite (1:2) for LIBs performs optimal initial capacity $\left(427 \mathrm{~mA} \mathrm{~h} \mathrm{~g}^{-1}\right)$ and cycling retention (58.7\% after 100 cycles). In addition, it also shows fine rate performance $177.1 \mathrm{~mA} \mathrm{~h} \mathrm{~g}^{-1}$ at $1 \mathrm{C}$ (recover to $299.3 \mathrm{~mA} \mathrm{~h} \mathrm{~g}^{-1}$ at $0.1 \mathrm{C}$ ). Based on these results, the strategy of composites can relieve the dissolution issue and optimize its electroconductivity. This method possesses great potential in enhancing organic materials' implementation on LIBs.

Received 1 February 2018; accepted 21 March 2018; published online 20 April 2018

1 Kim SW, Seo DH, Ma X, et al. Electrode materials for rechargeable sodium-ion batteries: potential alternatives to current lithium-ion batteries. Adv Energy Mater, 2012, 2: 710-721

2 Liang Y, Tao Z, Chen J. Organic electrode materials for rechargeable lithium batteries. Adv Energy Mater, 2012, 2: 742-769

3 Shi Y, Peng L, Ding Y, et al. Nanostructured conductive polymers for advanced energy storage. Chem Soc Rev, 2015, 44: 6684-6696

4 Zhang $\mathrm{K}, \mathrm{Hu} \mathrm{Z}$, Tao Z, et al. Inorganic \& organic materials for rechargeable Li batteries with multi-electron reaction. Sci China Mater, 2014, 57: 42-58

5 Wang C, Wang L, Li F, et al. Bulk bismuth as a high-capacity and ultralong cycle-life anode for sodium-ion batteries by coupling with glyme-based electrolytes. Adv Mater, 2017, 29: 1702212

6 Song Z, Zhou $\mathrm{H}$. Towards sustainable and versatile energy storage devices: an overview of organic electrode materials. Energy Environ Sci, 2013, 6: 2280

7 Nokami T, Matsuo T, Inatomi Y, et al. Polymer-bound pyrene4,5,9,10-tetraone for fast-charge and -discharge lithium-ion batteries with high capacity. J Am Chem Soc, 2012, 134: 19694-19700

8 Song Z, Qian Y, Gordin ML, et al. Polyanthraquinone as a reliable organic electrode for stable and fast lithium storage. Angew Chem Int Ed, 2015, 54: 13947-13951

9 Xie J, Wang Z, Gu P, et al. A novel quinone-based polymer electrode for high performance lithium-ion batteries. Sci China Mater, 2016, 59: 6-11

10 Morita Y, Nishida S, Murata T, et al. Organic tailored batteries materials using stable open-shell molecules with degenerate frontier orbitals. Nat Mater, 2011, 10: 947-951

11 Milczarek G, Inganäs $\mathrm{O}$. Renewable cathode materials from biopolymer/conjugated polymer interpenetrating networks. Science, 2012, 335: 1468-1471

12 Lin $\mathrm{K}$, Chen Q, Gerhardt MR, et al. Alkaline quinone flow battery. Science, 2015, 349: 1529-1532

13 Pletcher D, Heather Thompson A. Influence of electrolyte concentration on coupled chemical reactions Part 1 Reduction of $\mathrm{Co}^{\text {II }}$ (salen) in aprotic solvents. Faraday Trans, 1997, 93: 3669-3675

14 Chen $\mathrm{H}$, Armand $\mathrm{M}$, Demailly $\mathrm{G}$, et al. From biomass to a renewable $\mathrm{Li}_{x} \mathrm{C}_{6} \mathrm{O}_{6}$ organic electrode for sustainable $\mathrm{Li}$-ion batteries. ChemSusChem, 2008, 1: 348-355

15 Tarascon JM, Armand M. Issues and challenges facing rechargeable lithium batteries. Nature, 2001, 414: 359-367

16 Sun C, Liu J, Gong Y, et al. Recent advances in all-solid-state rechargeable lithium batteries. Nano Energy, 2017, 33: 363-386

17 Pirnat K, Mali G, Gaberscek M, et al. Quinone-formaldehyde polymer as an active material in Li-ion batteries. J Power Sources, 2016, 315: 169-178

18 Yao M, Araki M, Senoh $\mathrm{H}$, et al. Indigo dye as a positive-electrode material for rechargeable lithium batteries. Chem Lett, 2010, 39: 950-952

19 Zhu Z, Hong M, Guo D, et al. All-solid-state lithium organic battery with composite polymer electrolyte and pillar[5]quinone cathode. J Am Chem Soc, 2014, 136: 16461-16464

$20 \mathrm{Lu} \mathrm{Q}$, Wang X, Cao J, et al. Freestanding carbon fiber cloth/sulfur composites for flexible room-temperature sodium-sulfur batteries. Energy Storage Mater, 2017, 8: 77-84

21 Mao O. Active/inactive nanocomposites as anodes for Li-ion batteries. Electrochem Solid-State Lett, 1999, 2: 3-5

22 Lei Z, Wei-kun W, An-bang W, et al. A MC/AQ parasitic com- 
posite as cathode material for lithium battery. J Electrochem Soc, 2011, 158: A991

23 Li H, Duan W, Zhao Q, et al. 2,2'-Bis(3-hydroxy-1,4-naphthoquinone)/CMK-3 nanocomposite as cathode material for lithiumion batteries. Inorg Chem Front, 2014, 1: 193-199

24 Huang W, Zhu Z, Wang L, et al. Quasi-solid-state rechargeable lithium-ion batteries with a calix[4]quinone cathode and gel polymer electrolyte. Angew Chem Int Ed, 2013, 52: 9162-9166

25 Zheng S, Hu J, Huang W. An inorganic-organic nanocomposite calix[4]quinone (C4Q)/CMK-3 as a cathode material for high-capacity sodium batteries. Inorg Chem Front, 2017, 4: 1806-1812

26 Morita Y, Agawa T, Nomura E, et al. Syntheses and NMR behavior of calix[4]quinone and calix[4]hydroquinone. J Org Chem, 1992, 57: $3658-3662$

27 Okubo M, Hosono E, Kim J, et al. Nanosize effect on high-rate Liion intercalation in $\mathrm{LiCoO}_{2}$ electrode. J Am Chem Soc, 2007, 129: 7444-7452

28 Okubo M, Kim J, Kudo T, et al. Anisotropic surface effect on electronic structures and electrochemical properties of $\mathrm{LiCoO}_{2}$. J
Phys Chem C, 2009, 113: 15337-15342

Acknowledgements This work was supported by the National Natural Science Foundation of China (21403187), the Natural Science Foundation of Hebei Province of China (B2015203124) and the Key Laboratory of Advanced Energy Materials Chemistry (Ministry of Education), Nankai University.

Author contributions Zheng $\mathrm{S}$ wrote the paper. Hu J and Yan B prepared the calix[4]quinone (C4Q). Zheng S, Hu J collected the data and analyzed the results. Sun $\mathrm{H}$ provided the glovebox for cell assembling and TEM, FTIR, NMR tests. Huang W supervised the project, conceived the experiments, analyzed the results and wrote the paper. All authors contributed to the general discussion.

Conflict of interest These authors declare no conflict of interest.

Supplementary information Supporting data are available in the online version of the paper.

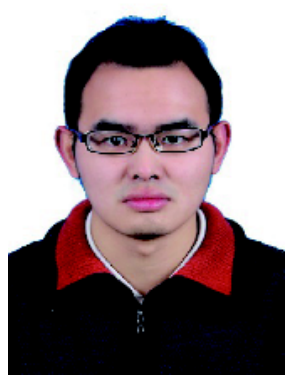

Shibing Zheng obtained his BSc degree at Hebei University of Engineering in China in 2015. He is currently a master candidate in Prof. Weiwei Huang's group at Yanshan University. His research focuses on the synthesis and fabrication of polymer electrode materials for Li/Na battery.

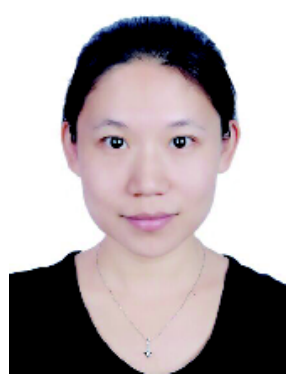

Weiwei Huang obtained her BSc degree at Hebei Normal University of Science \& Technology in China in 2005, MSc degree in inorganic chemistry at Hebei Normal University in 2008, and completed her PhD in physical chemistry at Nankai University in 2011. Then, she joined Prof. Chen Jun's group at Nankai University as a postdoctoral fellow. Since 2013, she joined the School of Environmental and Chemical Engineering at Yanshan University (Qinhuangdao) as an associate professor. Her research is focused on the organic electrode materials for Li/Na battery.

\section{高容量有机正极纳米复合材料calix[4]quinone/CMK-3锂离子电池}

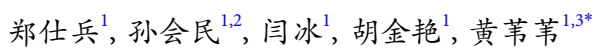

摘要 有机锂离子电池技术作为新一代能源储备技术具有环境友好、理论容量高的优点, 但也面临着活性材料溶于有机电解液的问题. 本研究将高容量活性材料calix [4] quinone(C4Q)以不同比例(1:3-3:1)负载到有序介孔碳CMK-3中得到纳米复合材料C4Q/CMK-3, 并通过 $\mathrm{XRD}, \mathrm{SEM}, \mathrm{TEM}$ 和BET实验手段对此复合材料进行了形貌和结构的表征. 当C4Q在复合材料C4Q/CMK-3的比重为 $33.3 \%$ (1:2)时, 其电化 学性能表现最佳. 首次循环放电容量为 $427 \mathrm{~mA} \mathrm{~h} \mathrm{~g}^{-1}$, 经过 100 次循环后, 放电容量保持率为 $58.7 \%$. 在大电流 $1 \mathrm{C}$ 充放电下, 容量也能保持在 $170.4 \mathrm{~mA} \mathrm{~h} \mathrm{~g}^{-1}$. 该研究结果证实了此优化方法可以用来改善有机材料的循环稳定性. 